\title{
Comparative Study of Indonesian Spectra Response Parameters for Buildings According To 2012 and 2019 Seismic Codes
}

\author{
Restu Faizah $^{1 *}$, Rahma Amaliah ${ }^{1}$ \\ ${ }^{1}$ Department of Civil Engineering, \\ Universitas Muhammadiyah Yogyakarta, Kasihan, Bantul, 55183, INDONESIA \\ *Corresponding Author
}

DOI: https://doi.org/10.30880/ijie.2021.13.03.020

Received 20 December 2020; Accepted 01 May 2021; Available online 06 June 2021

\begin{abstract}
The Indonesian government has determined a new seismic code for structural design of buildings and non-buildings, namely SNI 1726:2019. This new code is a revision of the previous code of 2012. The fundamental difference between the two seismic codes of 2012 and 2019 is in the earthquake hazard map (EHM) that was used. 2012 seismic code uses the EHM-2010, while 2019 seismic code uses the EHM-2017. The EHM-2017 has been updated by revising a data of subduction parameters and updating the number of active faults from 81 to 251 . This revision has an impact on increasing the spectral value of $S_{S}$ and $S_{1}$ which is a parameter that must be reviewed in structural planning. This study investigated the seismicity status of 34 cities in Indonesia by comparing the values of the spectra response parameters ( $S_{\mathrm{DS}}$ and $\mathrm{S}_{\mathrm{D} 1}$ ) according to seismic code of 2012 and 2019. This study found that the $S_{\mathrm{DS}}$ and $\mathrm{S}_{\mathrm{D} 1}$ value from 2012 to 2019 increased in 15 cities but decreased or remained in 19 other cities. The cities that experienced an increase of $S_{D S}$ and $S_{D 1}$ values were Bandar Lampung, Banjarmasin, Bengkulu, Gorontalo, Jayapura, Manokrawi, Medan, Palembang, Palu, Pangkal Pinang, Pontianak, Serang, Surabaya, Tanjung Selor, and Yogyakarta. It seems that the vulnerability assessment of the existing building in the 15 cities must be done to estimate their capacity under earthquake load designed by 2019 Seismic Code. Overall, Jayapura city has the highest of $\mathrm{S}_{\mathrm{DS}}$ and $\mathrm{S}_{\mathrm{D} 1}$ values in 2019 compared to the other cities.
\end{abstract}

Keywords: Seismic codes, earthquake hazard map, spectra response parameters, vulnerability assessment

\section{Introduction}

The condition of the Indonesian territory which is surrounded by four main plates, namely the Eurasian, IndoAustralian, Philippine, and Pacific Plate, resulted in the emergence of various earthquake sources located around the intersection of these plates. The number of earthquake sources increased after the discovery of new faults in several regions in Indonesia. Therefore, the Indonesian government has updated the seismic code for building from version 2012 to version 2019. This new code is SNI 1726:2019, The procedure of earthquake-resistant structure design for building and non-building. The main difference between the 2012 and 2019 seismic codes is the earthquake hazard map (EHM) used. The 2012 Seismic code uses the EHM-2010 [1], while the 2019 Seismic code uses the EHM-2017 [2]. There are several earthquake sources that have not been considered in the EHM-2010 design but were considered in the EHM-2017. Several large earthquakes that occurred after the determination of the EHM-2010 had not been accommodated in EHM-2010, including the earthquake in Mentawai 7.2 SR (2010), Simeuleu 8.5 SR (2012), Pidie jaya 6.5 SR (2016) and others [3]. Overall, there were 295 earthquake sources considered in the EHM-2017, whereas only 53 earthquake sources were considered in the EHM-2010. In addition, there was an increase in the number of 
active faults considered in EHM-2010 and 2017, from 81 to 251 [4]. This condition has resulted in an increase of seismic conditions of several cities in Indonesia after the implementation of 2019 seismic code.

Changes in seismic status will result in modification of earthquake loads in earthquake-resistant structural designs. The structure must be designed to have adequate strength to withstand earthquake loads according to the new EHM in 2017. Estimation of the structural strength requirements can be obtained from the spectral response curve specified in the seismic code. The spectrum response curve presents the relationship between the period of the structure and the maximum response of the structure such as the maximum of displacement, velocity, and acceleration [5].

To get a spectra response curve of a specific location, it must be determined the response spectrum parameters for a short period $\left(S_{D S}\right)$ and 1 second period $\left(S_{D 1}\right)$. These parameters are based on the $S_{S}$ and $S_{1}$ values obtained from the EHM. Therefore, changes in $S_{\mathrm{DS}}$ and $\mathrm{S}_{\mathrm{D} 1}$ values will result in modification of the spectra response curve which will be used to determine earthquake loads in structural design. For this reason, it is necessary to conduct the investigation of the changes of spectra response parameters in various cities in Indonesia which are determined from the 2012 and 2019 seismic codes. This study aims to compare the spectra response parameters generated from the 2012 and 2019 seismic codes in 34 cities in Indonesia. The results of this study are expected to predict seismic conditions of 34 cities in Indonesia which can be used as consideration for evaluating existing buildings that have been built according to the old seismic code in 2012.

Indonesia's seismic code has met several updates, which is in 1989, 2002, 2012, and 2019. Each update of the EHM has resulted in changes in seismic conditions in various sites, such as increasing or decreasing [6]. Comparison between 2002 and 2012 seismic codes in 23 major cities in Indonesia shows that $70 \%$ of cities experience an increase in seismic conditions [7]. The increase in peak acceleration of spectra response design from seismic code 2002 to 2012 in Madiun, Jawa Timur is $12.6 \%$ [8], but in Malang is $48.6 \%$ [9]. Based on previous research, it can be concluded that the 2012 seismic code is more acceptable for designing an earthquake-resistant building than the 2002 seismic code [10]. The Increasing seismic conditions at the site must be countered by re-evaluated of the structure to be designed and built in that location to meet the requirement of the latest seismic codes [11]. This phenomenon also occurs in various countries where updating of the seismic code has an impact on increasing seismicity in several locations [12]-[14].

\section{Research Methodology}

This research compares spectra response parameters generated from the 2012 and 2019 seismic codes in 34 cities representing all islands in Indonesia. Initially, city coordinates were determined using the Google Map application. Then the spectra response parameter values were determined, consisting the parameter on short period $\left(S_{S}\right)$ and 1 second period $\left(S_{1}\right)$ for each location, based on the 2012 and 2019 seismic codes. The $S_{S}$ and $S_{1}$ parameters can be identified using the spectra response design application issued by puskim.pu.go.id, but only for EHM-2010 in the 2012 seismic code. Meanwhile, the $S_{1}$ and $S_{S}$ parameters according to EHM-2017 in the 2019 seismic code must be determined manually using EHM-2017 as shown in Fig. 1 and Fig. 2.

If the values of $S_{S}$ and $S_{1}$ have been known, the parameters of spectra response design such as $S_{M S}, S_{M 1}, S_{D S}$, and $\mathrm{S}_{\mathrm{D} 1}$ can be calculated using Equation 1 to 4 . To determine $\mathrm{S}_{\mathrm{MS}}$ and $\mathrm{S}_{\mathrm{M} 1}$ using Equations 1 and 2, amplification factor data for a short period $(F a)$ and 1 second period $(F v)$ are required based on Tables 1 and 2. $F a$ and $F v$ are given for a specific of soil type, which is SA, SB, SC, SD, SE, and SF as presented in Table 1 and 2. The 2012 and 2019 seismic code defines 6 soil types, same with ASCE/SEI7/10 and Brazilian Standard [12]. From these parameters, the spectra response design can be generated as shown in Fig. 3. This method was adopted from ASCE 7-2016, The Minimum Design Loads and Associated Criteria for Buildings and other Structures [15].

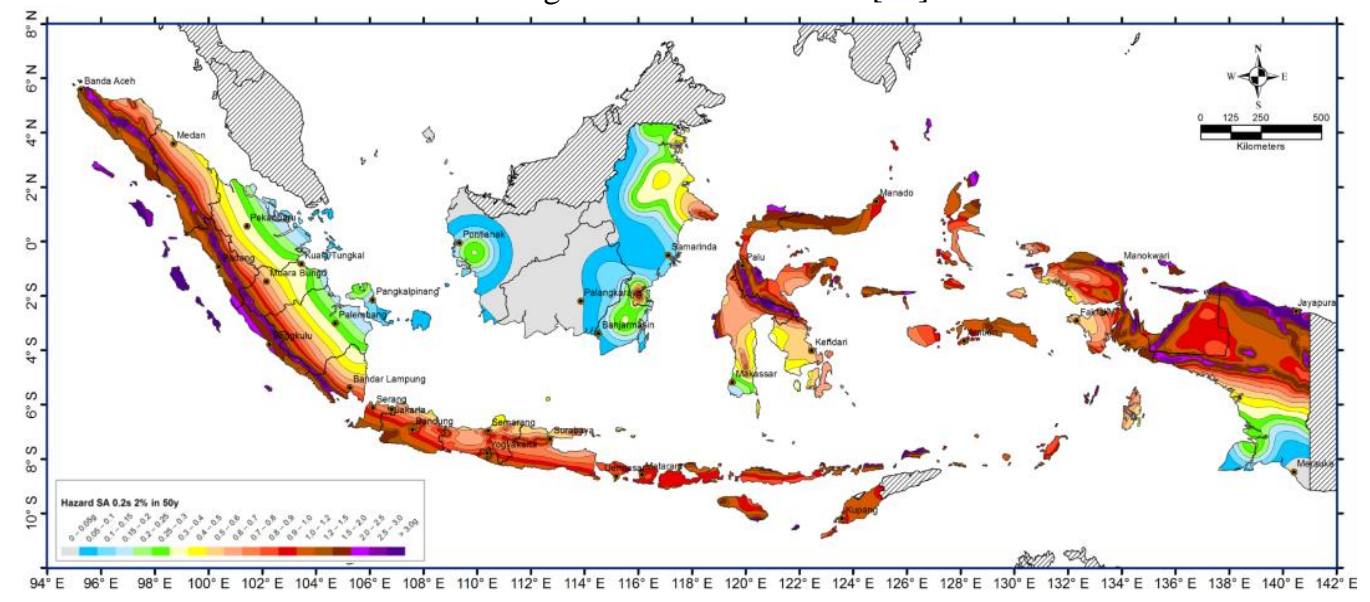

Fig. 1 - The map of spectral response acceleration on short period $(\mathrm{Ss})$, with $5 \%$ damping in bedrock for $2 \%$ probability of being exceeded in 50 years 


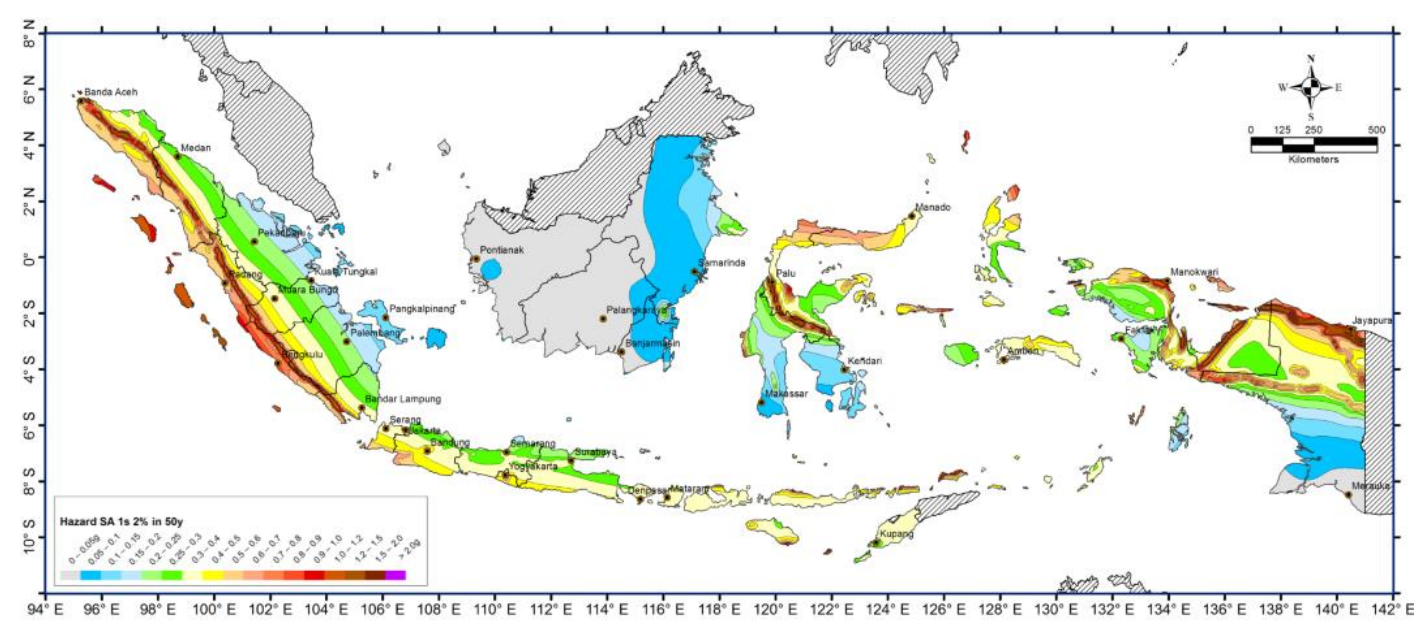

Fig. 2 - The map of the spectral response acceleration on 1 second period $\left(S_{1}\right)$, with $5 \%$ damping in bedrock for $2 \%$ probability of being exceeded in 50 years

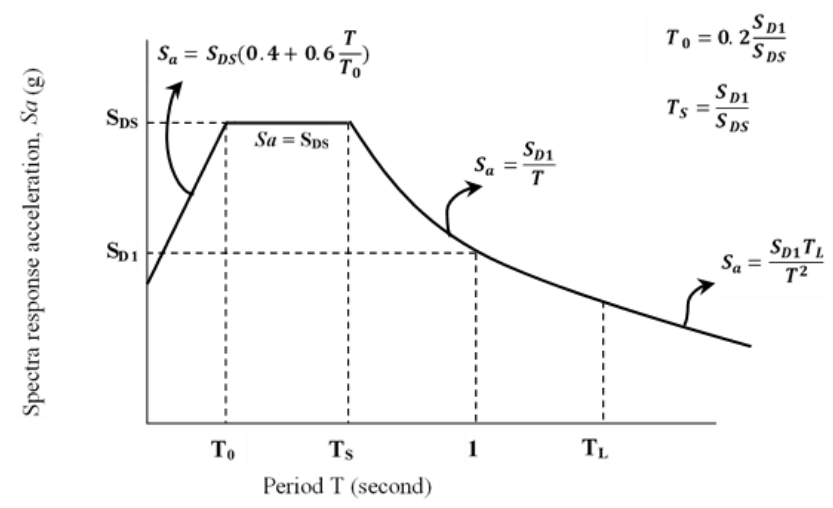

Fig. 3 - Spectra response acceleration $(\mathrm{Sa})$ in 2019 seismic code

$$
\begin{aligned}
& S_{M S}=F_{a} \cdot S_{s} \\
& S_{M 1}=F_{v} \cdot S_{1} \\
& S_{D S}=\frac{2}{3} \cdot S_{M S} \\
& S_{D 1}=\frac{2}{3} \cdot S_{M 1}
\end{aligned}
$$

$\mathrm{S}_{\mathrm{MS}}$ and $\mathrm{S}_{\mathrm{M} 1}$ are parameters of spectral acceleration on short period and 1 second period, $\mathrm{S}_{\mathrm{DS}}$ and $\mathrm{S}_{\mathrm{D} 1}$ are response

\begin{tabular}{|c|c|c|c|c|c|c|}
\hline \multirow[t]{2}{*}{ Site class } & \multicolumn{6}{|c|}{$\begin{array}{l}\text { Spectral response parameter of earthquake acceleration (MCER) on } \\
\text { short period, } T=0,2 \mathrm{~s}, \mathrm{~S}_{\mathrm{s}}\end{array}$} \\
\hline & $\mathrm{S}_{\mathrm{s}} \leq 0.25$ & $\mathrm{~S}_{\mathrm{S}}=0.5$ & $\mathrm{~S}_{\mathrm{S}}=0.75$ & $\mathrm{~S}_{\mathrm{S}}=1.0$ & $S_{s}=1.25$ & $\mathrm{Ss}_{\mathrm{s}} \geq \mathbf{1 . 2 5}$ \\
\hline Hard rock $(\mathrm{SA})$ & 0.8 & 0.8 & 0.8 & 0.8 & 0.8 & 0.8 \\
\hline Rock (SB) & 0.9 & 0.9 & 0.9 & 0.9 & 0.9 & 0.9 \\
\hline Hard soil (SC) & 1.3 & 1.3 & 1.2 & 1.2 & 1.2 & 1.2 \\
\hline Medium soil (SD) & 1.6 & 1.4 & 1.2 & 1.1 & 1.0 & 1.0 \\
\hline Soft soil (SE) & 2.4 & 1.7 & 1.3 & 1.1 & 0.9 & 0.8 \\
\hline Special soil (SF) & \multicolumn{6}{|c|}{$\mathrm{SS}^{(\mathrm{a})}$} \\
\hline
\end{tabular}
spectrum parameters for a short period and 1 second period, $S_{S}$ and $S_{1}$ are spectra response parameters on short period and 1 second period, while $F a$ and $F v$ are amplification factors for a short period and 1 second period.

Table 1 - Site coefficient, $F_{a}(2019$ seismic code) 
Table 2 - Site coefficient, $F v$ (2019 seismic code)

\begin{tabular}{lcccccc}
\hline \multirow{2}{*}{\multicolumn{1}{c}{ Site class }} & \multicolumn{6}{c}{ Spectral response parameter of earthquake acceleration (MCER) on } \\
& \multicolumn{5}{c}{ 1s period, $\mathbf{T}=\mathbf{1 s}, \mathbf{S}_{\mathbf{1}}$} \\
\cline { 2 - 6 } & $\mathrm{S}_{1} \leq 0.1$ & $\mathrm{~S}_{1}=0.2$ & $\mathrm{~S}_{1}=0.3$ & $\mathrm{~S}_{1}=0.4$ & $\mathrm{~S}_{1}=0.5$ & $\mathrm{~S}_{1} \geq 0.5$ \\
\hline Hard rock (SA) & 0.8 & 0.8 & 0.8 & 0.8 & 0.8 & 0.8 \\
Rock (SB) & 0.8 & 0.8 & 0.8 & 0.8 & 0.8 & 0.8 \\
Hard soil (SC) & 1.5 & 1.5 & 1.5 & 1.5 & 1.5 & 1.4 \\
Medium soil (SD) & 2.4 & 2.2 & 2.0 & 1.9 & 1.8 & 1.7 \\
Soft soil (SE) & 4.2 & 3.3 & 2.8 & 2.4 & 2.2 & 2.0 \\
Special soil (SF) & \multicolumn{5}{c}{$\mathrm{SS}^{(\text {(a) }}$} \\
\hline
\end{tabular}

(a) $\mathrm{SS}=$ The site needing a specific of geotechnical investigation and response site analysis.

\section{Result and Discussion}

The response spectra design parameters discussed in this study consisted of $\mathrm{S}_{\mathrm{DS}}$ and $\mathrm{S}_{\mathrm{D} 1}$. These parameters are reviewed in 34 cities in Indonesia with 3 variations of soil types, namely hard soil (SC), medium soil (SD), and soft soil (SE). In the discussion, these parameters are compared between the conditions according to the 2012 and 2019 seismic codes.

\subsection{Comparison of SDs value of 2012 and 2019}

Fig. 4 to Fig. 6 show the comparison of $S_{D}$ values of 2012 and 2019 in 34 cities for 3 soil types, SC, SD, and SE. From left to right in the figure shows the city that experienced the largest decrease to the largest increase. The highest $\mathrm{S}_{\mathrm{DS}}$ value in 2012 was in Palu city with the values of $1.4 \mathrm{~g}$ for SC/SD and $1.3 \mathrm{~g}$ for SE soil types. The highest value in 2019 moved to Jayapura City with a value of $2.2 \mathrm{~g}$ for SC/SD and 2.0g for SE soil types. Jayapura has experienced an increase in $S_{D S}$ values from 2012 to 2019 by $120 \%$ for all types of soil. Although the increase in Jayapura of $S_{D S}$ value was less than Pangkal Pinang and Pontianak, the risk of building due to the earthquake in Jayapura was the highest. This is because the $S_{\mathrm{DS}}$ values in Pangkal Pinang and Pontianak are relatively small. Pontianak City experienced an increase in $S_{\mathrm{DS}}$ value from 2012 to 2019 by around $1000 \%$. However, the $\mathrm{S}_{\mathrm{DS}}$ value in 2019 were only $0.14,0.2$, and 0.3 for hard, medium, and soft soils, respectively.

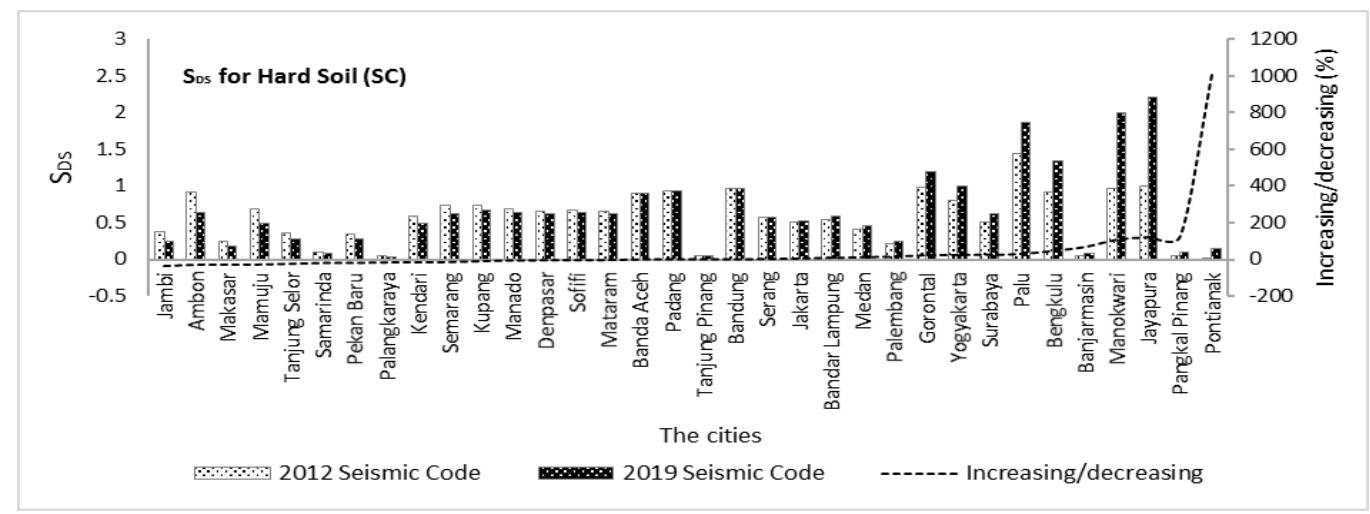

Fig. 4 - Comparison of SDs value of 2012 and 2019 in 34 cities for hard soil (SC)

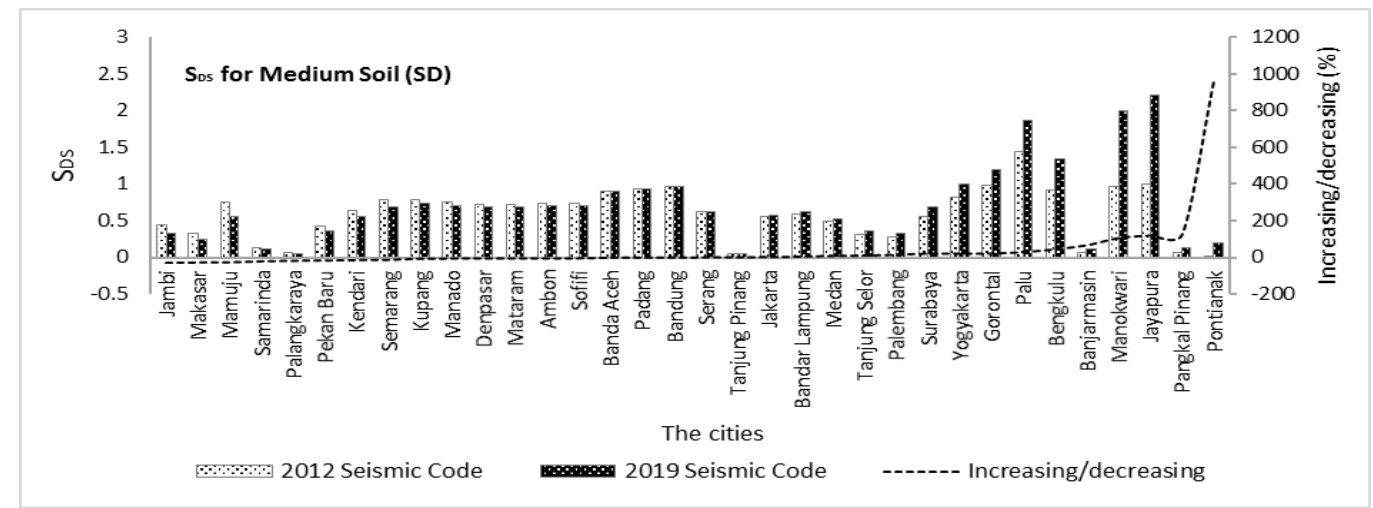

Fig. 5 - Comparison of SDS value of 2012 and 2019 in 34 cities for medium soil (SD) 


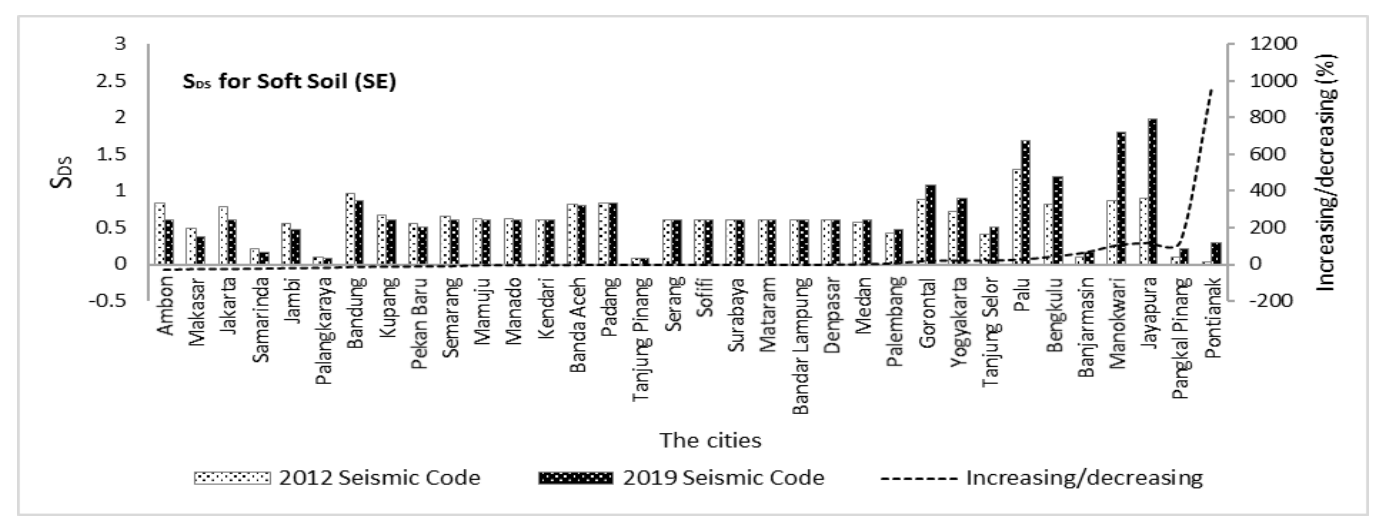

Fig. 6 - Comparison of SDs value of 2012 and 2019 in 34 cities for soft soil (SE)

There were 15 cities that experienced an increase in $S_{D S}$ values from 2012 to 2019, but 19 other cities experienced a decline or remain. The cities that experienced an increase in $S_{D S}$ values were Bandar Lampung, Banjarmasin, Bengkulu, Gorontalo, Jayapura, Manokrawi, Medan, Palembang, Palu, Pangkal Pinang, Pontianak, Serang, Surabaya, Tanjung Selor, and Yogyakarta. The $\mathrm{S}_{\mathrm{DS}}$ value can describe the peak of spectral response acceleration $(\mathrm{Sa})$ in the site. This indicates that the existing buildings built after 2012 need to be re-evaluated using the new seismic code of 2019 . To explain this case, the spectra response design of Jayapura is also illustrated in the last part of the discussion.

\subsection{Comparison of $S_{D 1}$ Value of 2012 and 2019}

Fig. 7 to Fig. 9 show the comparison of $S_{D 1}$ values in 2012 and 2019 in 34 cities for 3 types of soil, SC, SD, and $\mathrm{SE}$. From left to right in the figure shows the city that experienced the largest decrease to the largest increase. The highest $\mathrm{S}_{\mathrm{D} 1}$ values in 2012 were $0.6 \mathrm{~g}, 0.8 \mathrm{~g}$, and $1.2 \mathrm{~g}$, while in 2019 they were $1.3 \mathrm{~g}, 1.5 \mathrm{~g}$, and $2.4 \mathrm{~g}$ respectively for SC, SD, and SE. The city with the highest $\mathrm{S}_{\mathrm{D} 1}$ value was Palu in 2012, however, in 2019, it was Palu and Jayapura with the same value. It can be seen that the softer of the soil type, it have the higher of the $S_{\mathrm{D} 1}$ value. This indicates that earthquake vibrations will result in greater base shear on the structure if the soil beneath the structure is softer. Of the 34 cities reviewed, 15 cities experienced an increase in $S_{\mathrm{D} 1}$ values from 2012 to 2019 , while 19 other cities tended to remain and decline. The 15 cities that experienced an increase in $S_{D 1}$ values from 2012 to 2019 are the same as cities that experienced an increase in $S_{D S}$ values.

Learning from the Palu City, which has high parameters of spectra response, in 2018 it experienced a large earthquake followed by a tsunami. This earthquake is thought to have been caused by the Palu Koro fault activity, which is the longest fault in Sulawesi Island with an extending direction from Central Sulawesi to the Karimata Strait.

Although the $S_{D 1}$ value in 2019 is the same, the increase in $S_{D 1}$ value from 2012 to 2019 in Jayapura city is higher than in Palu, which is 50\% for Jayapura and $96 \%$ for Palu for all types of soil. The increase in the $S_{D 1}$ value in Jayapura may be due to the increase in earthquake sources found after 2010. The number of earthquake sources in Papua considered in EHM-2010 was 12, however, in EHM-2017 it increased to 48 earthquake sources [4]. The increase in the $\mathrm{S}_{\mathrm{D} 1}$ value in Jayapura can be taken into consideration for the evaluation of existing buildings.

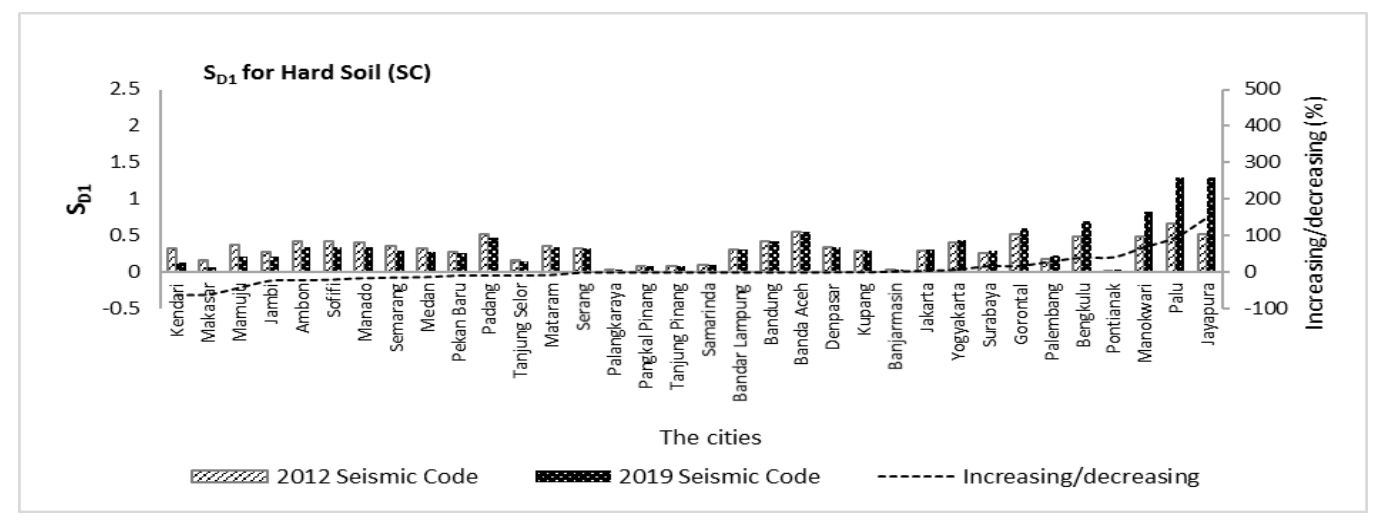

Fig. 7 - Comparison of SD1 value of 2012 and 2019 in 34 cities for hard soil (SC) 


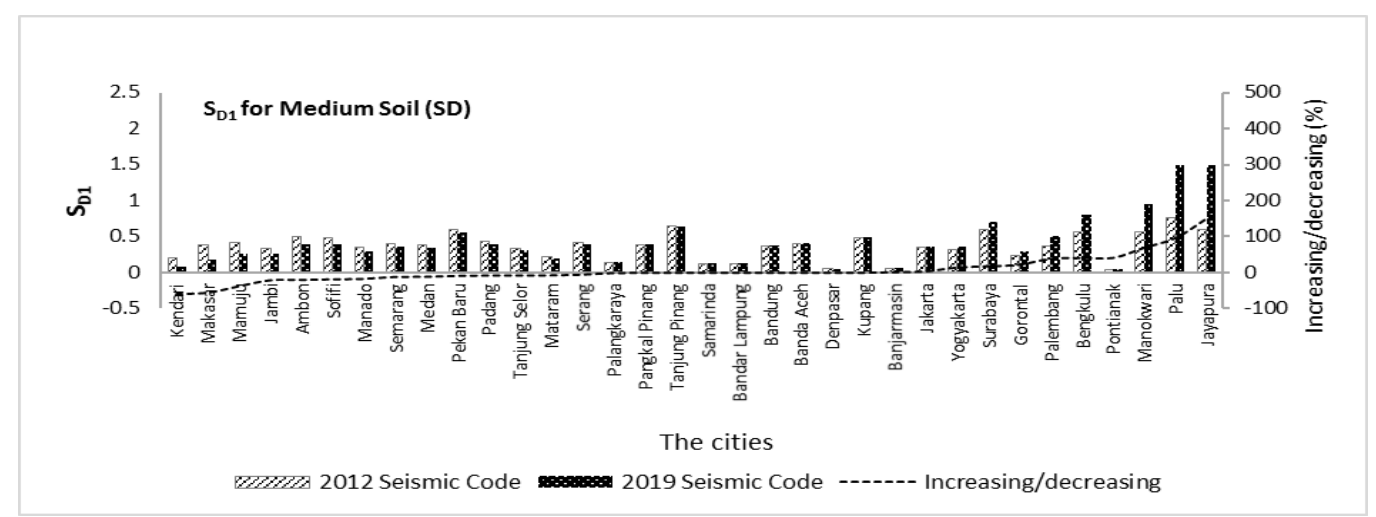

Fig. 8 - Comparison of SD1 value of 2012 and 2019 in 34 cities for medium soil (SD)

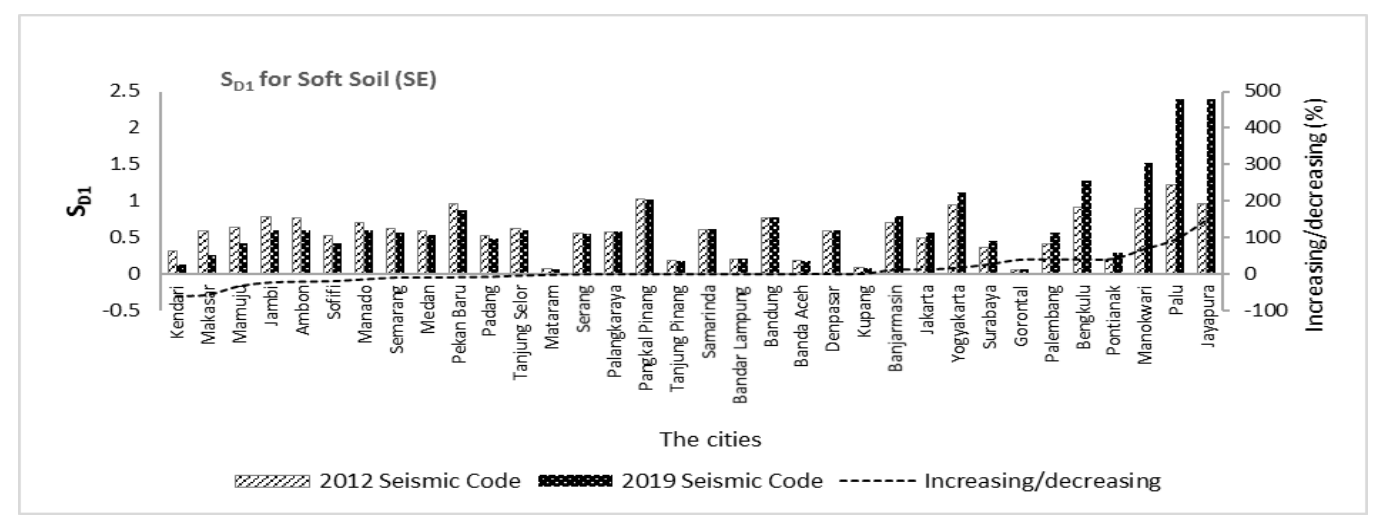

Fig. 9 - Comparison of SD1 value of 2012 and 2019 in 34 cities for soft soil (SE)

\subsection{Spectra Response Design of Jayapura}

The spectra response design (SRD) of Jayapura City can be drawn based on the $\mathrm{S}_{\mathrm{DS}}$ and $\mathrm{S}_{\mathrm{D} 1}$ values. Fig. 10 shows the comparison of Jayapura's SDR between hard, medium and soft soils in 2012 and 2019. The maximum $S a$ value in Fig. 10(b) appears to be higher than Fig. 10(a) by about twice as much. This indicates an increase in the $\mathrm{S}_{\mathrm{DS}}$ value of Jayapura by $120 \%$ so that existing buildings designed based on the 2012 seismic code should be evaluated for their vulnerability to 2019 earthquake loads. The increase in the value of $S a$ is not equal for all structures, depending on the natural period of the structure. Fig. 11(a)-(c) show the comparison of the Jayapura's SRD between 2012 and 2019 , for structures built on hard, medium and soft soils, respectively. The maximum increase in the $\mathrm{S}_{\mathrm{DS}}$ value of Jayapura City was experienced by buildings with a natural period of $0.12-0.59$ seconds (on hard soil), $0.14-0.68$ seconds (on medium soil) and $0.24-1.21$ seconds (on soft soil). Therefore, buildings that have a natural period as mentioned above are most important to re-evaluate their vulnerability. In the case study of structural design in Jayapura City, it was found that structures with a natural period of 2.79 seconds experienced an increase in base shear according to EHM2017 by $60 \%$ compared to EHM-2010 [16].
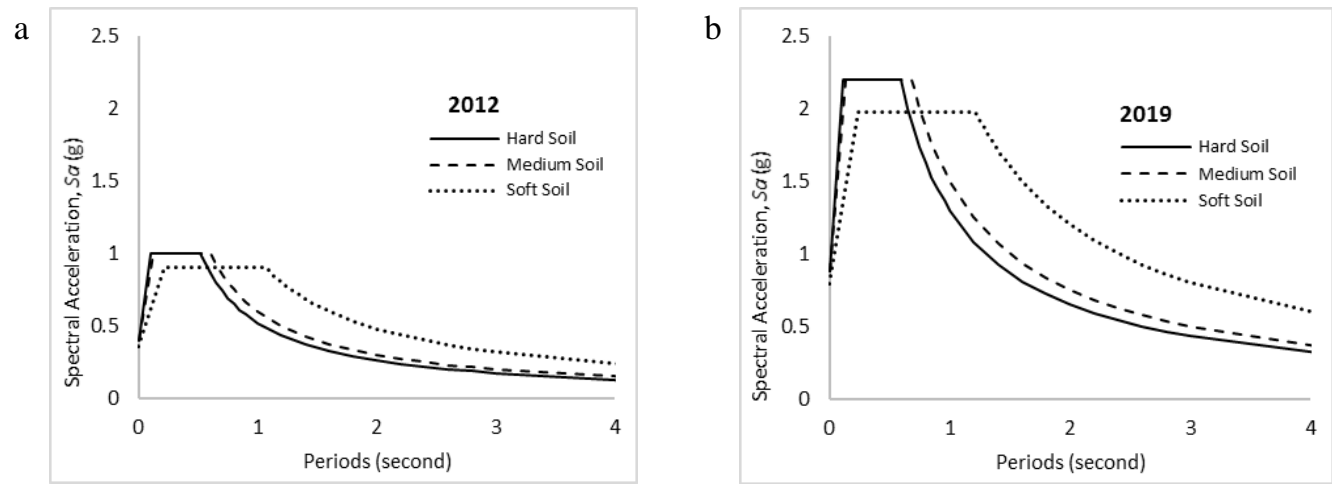

Fig. 10 - Comparison of Jayapura's SRD between hard, medium, and soft soil in 2012 and 2019 in (a) 2012; (b) 2019 

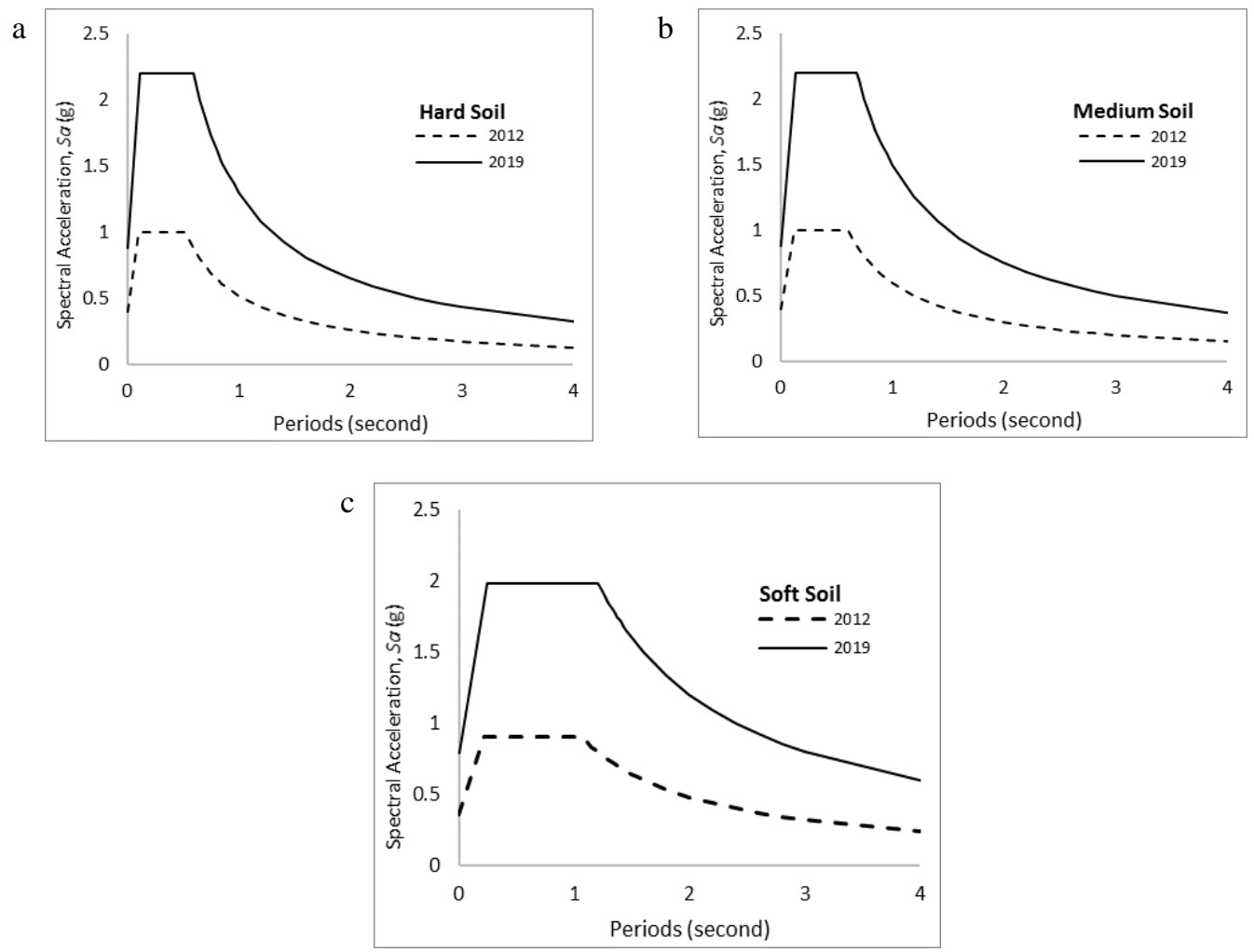

Fig. 11 - Comparison of Jayapura's SRD between 2012 and 2019 for hard, medium, and soft soil (a) Hard soil; (b) Medium soil; (c) Soft soil

\section{Conclusion}

Comparison of spectra response parameter values in 2012 and 2019 in 34 cities has been presented and complemented by a case study of the spectra response design in Jayapura City. Based on this discussion, the following can be concluded:

- There were 15 cities that experienced an increase in $S_{D S}$ and $S_{D 1}$ values from 2012 to 2019, but 19 other cities experienced a decline or remain.

- The 15 cities that experienced an increase in $S_{D S}$ and $S_{D 1}$ values were Bandar Lampung, Banjarmasin, Bengkulu, Gorontalo, Jayapura, Manokrawi, Medan, Palembang, Palu, Pangkal Pinang, Pontianak, Serang, Surabaya, Tanjung Selor, and Yogyakarta

- The vulnerability assessment of the existing building in the 15 cities must be done to estimate their capacity under earthquake load designed by SNI 1726:2019.

- Jayapura has the highest of $S_{D S}$ and $S_{D 1}$ values in 2019 compared to the other cities.

- Buildings located in Jayapura which have a natural period of 0.12 - 0.59 seconds (on hard soil), $0.14-0.68$ seconds (on medium soil) and $0.24-1.21$ seconds (on soft soil) has a priority to re-evaluate its vulnerability to the 2019 earthquake load.

\section{Acknowledgement}

Author would like to thank the Universitas Muhammadiyah Yogyakarta for their support in this research. Awards were also given to Rahma Amaliah who has carried out the analysis in this research.

\section{References}

[1] SNI 1726:2012 (2012). The procedure of Earthquake Resistance Design for Building and Non-Building Structures (in Bahasa). Indonesian Standard

[2] SNI 1726:2019 (2019). The procedure of Earthquake Resistance Design for Building and Non-Building Structures (in Bahasa). Indonesian Standard

[3] Asrurifak (2017). Indonesia's Earthquake Hazard Map of 2017 and Its Application for Earthquake Resistant Building and Infrastructure Design (in Bahasa). Workshop of Earthquake Disaster Risk Reduction (DRR) for Surabaya City and East Java. Institut Teknologi Sepuluh Nopember 
[4] Pusgen and Puslitbang PUPR (2017). The 2017 Source and Earthquake Hazard Map of Indonesia (in Bahasa). Puslitbang PUPR

[5] Pawirodikromo W. (2012). Seismology and Earthquake Engineering (in Bahasa). Pustaka Pelajar

[6] Cornelis R. \& Bunganaen W. (2014). Comparative study of story shear, base shear, story displacement, and drift ratio due to the earthquake load according to SNI 1726-2002 and SNI 1726-20122 (in Bahasa). Journal of Civil Engineering, VIII, 2015-2016

[7] Faizah R. \& Widodo. (2013) Analysis of earthquake forces design on multi story structures using dynamic response spectra method (in Bahasa). Proceeding of 7th Civil Engingeering Conference (Konteks 7), Solo

[8] Suleman N. S. \& Masagala A. A. (2015). Comparative study of multi-storey structure design based on the SNI 1726: 2002 and SNI 1726: 2012 (in Bahasa). Jurnal TeknoSAINS Seri Teknik, 1-12

[9] Lailasari D. N., Wibowo A. \& Nuralinah D. (2015). Comparative study of earthquake resistant building design using SNI 03-1726-2002 and SNI 03-1726-2012 (in Bahasa). Proceeding of National Seminar for Student on Universitas Brawijaya, Malang, Indonesia

[10] Jokhu P. D., Wibowo A. \& Wijaya M. N. (2016). Evaluation of structural performance under earthquake according to SNI 03-1726-2012 and SNI 03-1726-2002, case study: PTIIK building on Universitas Brawijaya (in Bahasa). Journal of Civil Engineering, Universitas Brawijaya, 1, 1-10

[11] Suprobo P. (2016). The Effect of Updating the Indonesian Earthquake Hazard Map on the Level of Structure Performance (LRT) (in Bahasa), Workshop of Earthquake Disaster Risk Reduction (DRR) for Surabaya City and East Java. Institut Teknologi Sepuluh Nopember

[12] Santos S. H. C., Giarlelis C., Traykova M., Bucur C., Zanaica L. \& Lima S. S. (2017). Comparative study of a set of codes for the seismic design of buildings. Proceeding of the 39th IABSE Symposium-Engineering the Future, Vancouver, pp. 1-8

[13] Santos S. H. C., Zanaica L., Bucur C, Lima S. D. S., \& Arai A. (2013) Comparative study of codes for seismic design of structures. Mathematical Modelling in Civil Engineering, 9(1), 1-12

[14] Dhanvijay V., Telang D. \& Nair V. (2015). Comparative Study of Different Codes in Seismic Assessment. International Research Journal of Engineering and Technology, 2(04), 1371-1381

[15] ASCE (2017). Minimum Design Loads and Associated Criteria for Buildings and Other Structures (ASCE 7-16), American Society of Civil Engineer

[16] Faizah R. \& Saputra E. (2018). Seismic demand due to the earthquake hazard map 2017 determination in Indonesia. Proceeding of the 7th Engineering International Conference on Education, Concept and Application on Green Technology, Semarang. http://doi.10.5220/0009007101080116 